\title{
A Novel Course To Provide Electrical Engineering Experience
}

To

Freshmen Students

\author{
Hirak C. Patangia \\ University of Arkansas at Little Rock \\ hcpatangia@ualr.edu
}

\begin{abstract}
$\underline{\text { Abstract }}$
An experiential learning course centered around an intellectually inquisitive project has been designed to introduce freshmen students to the field of electrical engineering, and also to provide the students with a head start for the beginning engineering courses they will take later in the curriculum. The course has a heavy emphasis on laboratory activities with an equally strong focus on 'just-in-time' theory relating to the concepts central to accomplishing the project goal. The prerequisites for the course have been kept at a minimum to make the course accessible to any university student who wants to explore engineering as a career.
\end{abstract}

\section{$\underline{\text { Introduction }}$}

In a traditional engineering curriculum, students devote their freshmen year to taking math and science courses to prepare them for the engineering courses to come later in the curriculum. Such an approach is often dry and not motivating to the freshmen since they don't see any application courses. In addition, the students have to wait a year or more to know if the major they have chosen will meet their career goals. The traditional 'introduction to engineering' course that generally surveys various engineering career paths is insufficient to provide the freshmen students with a feel for their major. As an alternate, many engineering programs have started offering project-based courses under various titles at the freshmen level to introduce students to the field of their study. A leading institution to introduce such an approach in the ECE curriculum is Carnegie Mellon University, and they have successfully offered an intellectually substantive' course with basic algebra and high school physics as prerequisites ${ }^{1}$.

Unlike the courses specifically designed to provide freshmen experiential learning to the majors admitted into a program, the course described in this paper has the following objectives:

- The course is accessible to any university student who has knowledge of basic algebra and who wants to explore electrical engineering through experiential learning.

- The course will provide a 'taste of electrical engineering' for the students to decide if they indeed want to major in the field of electrical engineering.

- The course will have a significant intellectual component that will prepare them for courses to come later in the curriculum.

- The course will provide significant laboratory experience for the students to be competent in the use of basic electronic instruments.

- The course will focus on engineering creativity for students to stay motivated in their field of study. 
- The course materials are to be presented in a way that the students learn to understand each piece of the puzzle in a hierarchical way before they assemble all the pieces necessary to complete the project goal.

- The course will employ a black-box teaching approach with ideal input-output relationship when appropriate.

- The course will emphasize team building, cooperative leaning, and oral/written communication skills.

\section{Course Organization}

The course titled 'Introductory Experience in Technology and Computers' is a three credit hour course with five contact hours per week, two hours of lecture and three hours of laboratory. The lecture and laboratory contents have been designed to lead the students to a culminating project which is described in the next section. The teaching classroom is a welldesigned facility with wireless internet access and the laboratory is equipped with modern Agilent test equipment. The course was first taught in the fall of 2001. Preparations for the course began in the summer of 2001 with a curriculum development grant from the university. Three sophomore students (two electrical and one mechanical) were selected to work with the faculty in developing a working prototype of the project. The selection of sophomore students was deliberate since they will be more in tune with the background and expectations of freshmen than upper level students. The three students also served as a preparatory audience for the course to provide input in determining the flow, complexity, and relevance of the selected topics for the course. The students were later employed as laboratory assistants in the delivery of the course. The following is a course outline for the fall 2001 offering:

- Introduction to engineering through the eyes of industries.

- Engineering design process and project outline.

- Basic circuit quantities: current, voltage, power, and energy; dc and ac source; circuit symbols.

- Basic circuit elements: resistor, capacitor, and inductor; Ohm's law.

- Resistive circuits: resistors in series and parallel; series-parallel reduction; shorts, open, and common reference point.

- Circuit laws: Kirchoff's voltage and current laws and applications.

- Fundamentals of ac quantities: characterization; peak, average, and rms values; timeperiod and frequency.

- Operational amplifiers: black-box approach and ideal model; basic concept of feedback; inverting and non-inverting configurations with applications.

- Comparators: operational amplifier in the open loop configuration with applications.

- Diodes: v-i relationship using piecewise linear model; basic semiconductor overview; rectifying diodes, light emitting diodes, infrared and photo-diodes.

- Transistors: 3-terminal black-box model; transistor as an amplifier and switch.

- Feedback control: basic concept; pulse-width control with feedback.

- Microcontrollers: introduction to microcontrollers using Basic Stamp II. 
Ten laboratory exercises were developed to reinforce the lecture through hands-on experience. Each lab was designed to have two components: a step-by-step procedure to reinforce theoretical understanding and an 'explore' section where students look at practical applications. Such an approach holds students' interests and also useful in recruiting prospective students to engineering. The following is a list of the experiments developed for the course:

- Resistor Color Code and Use of DMM. Explore the effect of dimension on the resistance value through students' own design.

- Voltage and Current Measurements using DMM. Explore series and parallel connections of Christmas lights using LEDs.

- Electromagnet. Explore the effect of a hand-wound electromagnet of 500ft of magnet wire, wrapped around a household steel bolt, on a lightweight steel ball.

- Familiarization with Agilent 5421A Oscilloscope. Explore the maximum operating frequency of the electromagnet built in the previous lab.

- Introduction to Operational Amplifier. Explore volume control of a CD player.

- Op-amp Voltage Comparator. Explore a go/no go battery tester for $1.5 \mathrm{~V}$ and $9 \mathrm{~V}$ batteries.

- Diode Circuits. Explore a dc power supply.

- Introduction to Transistors. Explore the transistor as a switch to control Christmas lighting.

- Pulse-Width Modulation. Explore an electronic dimmer and speed control of a dc motor.

- Schematic Drawing using PSPICE.

The laboratory write-ups were handed to the students after each lecture and the students were required to have a journal for data logging. Knowing that the freshmen students have very little prior laboratory experience, every effort was made to minimize laboratory frustrations by using multiple lab assistants.

\section{Course Project: Magnetic Levitation of a Ball}

The project selected for the course for the first offering was to levita te a lightweight ball in free space. To make the project more educational and fulfilling for the students, it was decided that the students would learn the fundamentals to design their own levitation system rather than using a commercial kit. The motivation for selecting the ball levitator project is that the students intuitively understand the basic requirement of balancing the force of gravity. The magnetic levitation of a lightweight object such as a steel ball has received much attention from hobbyists, experimentalists, and as a science fair high school project. Extensive web-based resources on this topic are available ${ }^{2}$. The theoretical design and analysis of a magnetic levitation system, however, is rather complex due to the nonlinearity of the magnetic field ${ }^{3}$. Our goal of the project is for students to learn the fundamentals of circuit theory, electronic devices, and feedback control concepts central to the project requirement while avoiding math beyond the algebra level. In addition, project construction required elements of mechanical design for housing the levitation system. The following figure is a block diagram of the project configuration and a starting point for the students. 


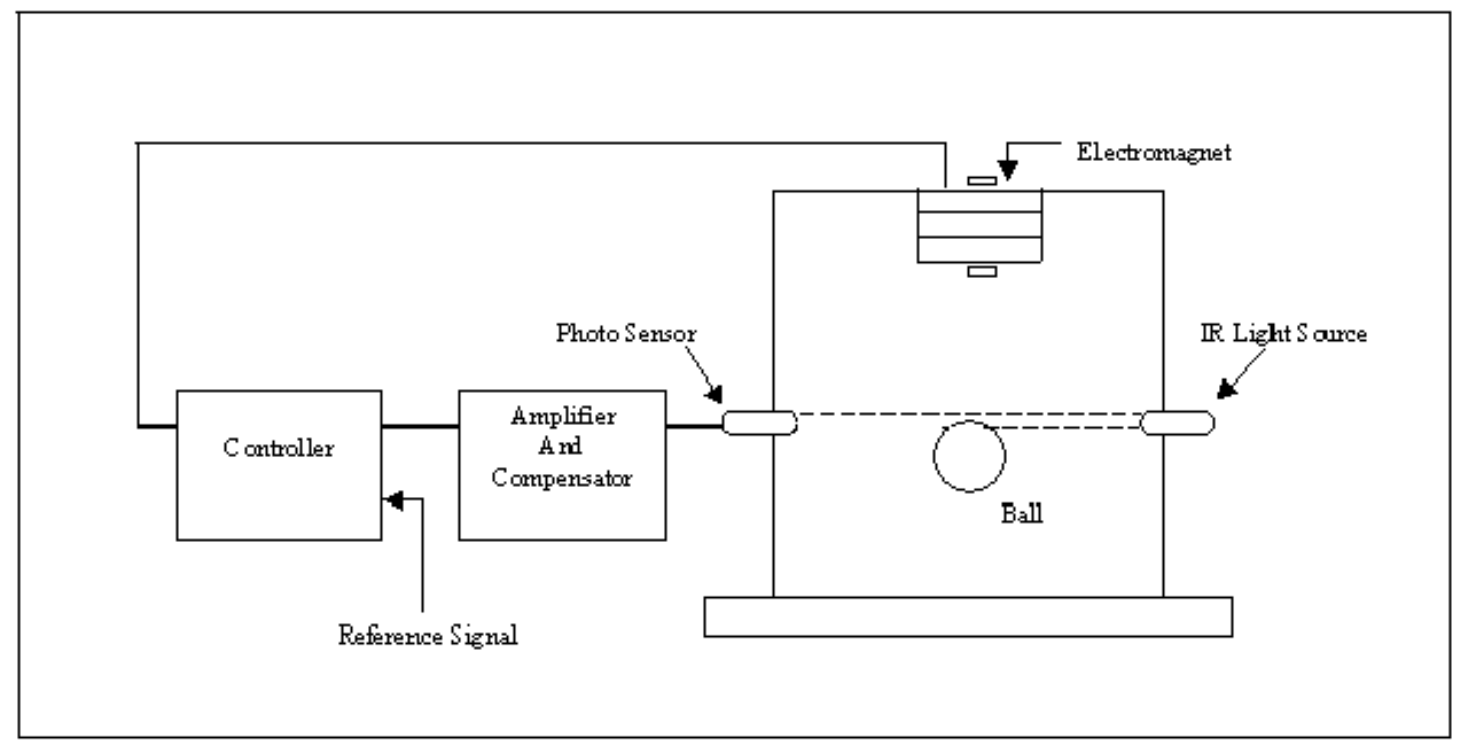

Magnetic Ball Levitator System

To preserve stability, a feedback system is used in which the position of the ball is continuously monitored and any deviation from the balanced position provides a control signal to enhance or reduce the pulse current through the electromagnet. This in turn adjusts the electromagnetic force in a way that the ball remains in a stable position. The students constructed the frame using wood or aluminum, and the positions of the IR LED and the photo sensor were made adjustable by mounting them in sliding holders along the two posts. For the ball, students used jingle bells or hollow balls that are normally found attached to key chains. Pulse-width modulation was used to control the magnet current, and a signal generator provided a triangular reference waveform for linear pulse-width variation. The students learned to design each block of the system using the concepts that were taught throughout the course. The circuitry for implementation was deliberately simplistic in design so that the students fully understand the system components and correlate them to classroom instructions. The purpose of the compensating network in the feedback path was discussed, and the students were provided with its design. They observed the effect of the compensator on the stability of the ball through experimentation.

\section{Course Delivery}

The students were introduced to the project on the first day of class, and were shown a working model. It gave them confidence about the feasibility of the project and also an indication of what to expect at the completion of their work. All the components were explained in a simplistic way at the block diagram level.

Due to the unique nature of the course, no textbook was adopted. The students relied on regular lecture note handouts and web resources. They were given regular homework assignments and these were graded on a weekly basis. Class quizzes were given once a week and they had regular feedback on their progress. Cooperative learning was encouraged and the lab assistants gave them tutorial help when needed. Along with the homework 
assignments, laboratory work was also graded in a timely manner. There was no comprehensive final for the course. The last three and a half weeks of the 15 -week semester was devoted primarily to the project work. With the classroom and laboratory experience students had so far, they were generally comfortable in designing and putting together their project work. The students found out that the positions of the sensors were critical in the levitation of the ball. Through some frustrations and trial and error, eventually every group made their project work.

Each group was required to write formal reports describing their project work and the guidelines for the formal reports were clearly explained. They submitted draft copies of their reports for review and these were corrected/commented by the faculty before the students finalized their reports. Class members made use of the digital camera available in the lab to take pictures of their projects and included them in the reports. The students were required to make formal presentations describing their projects. Interested faculty and administrators were invited to the presentations. The presentations were followed by a demonstration of the working model. The overall letter grade was based on their performance in quizzes, laboratory work, project work, written and oral presentation, and classroom participation.

\section{$\underline{\text { Project Demonstration }}$}

The following pictures are included to give a view of the students' project demonstrations:
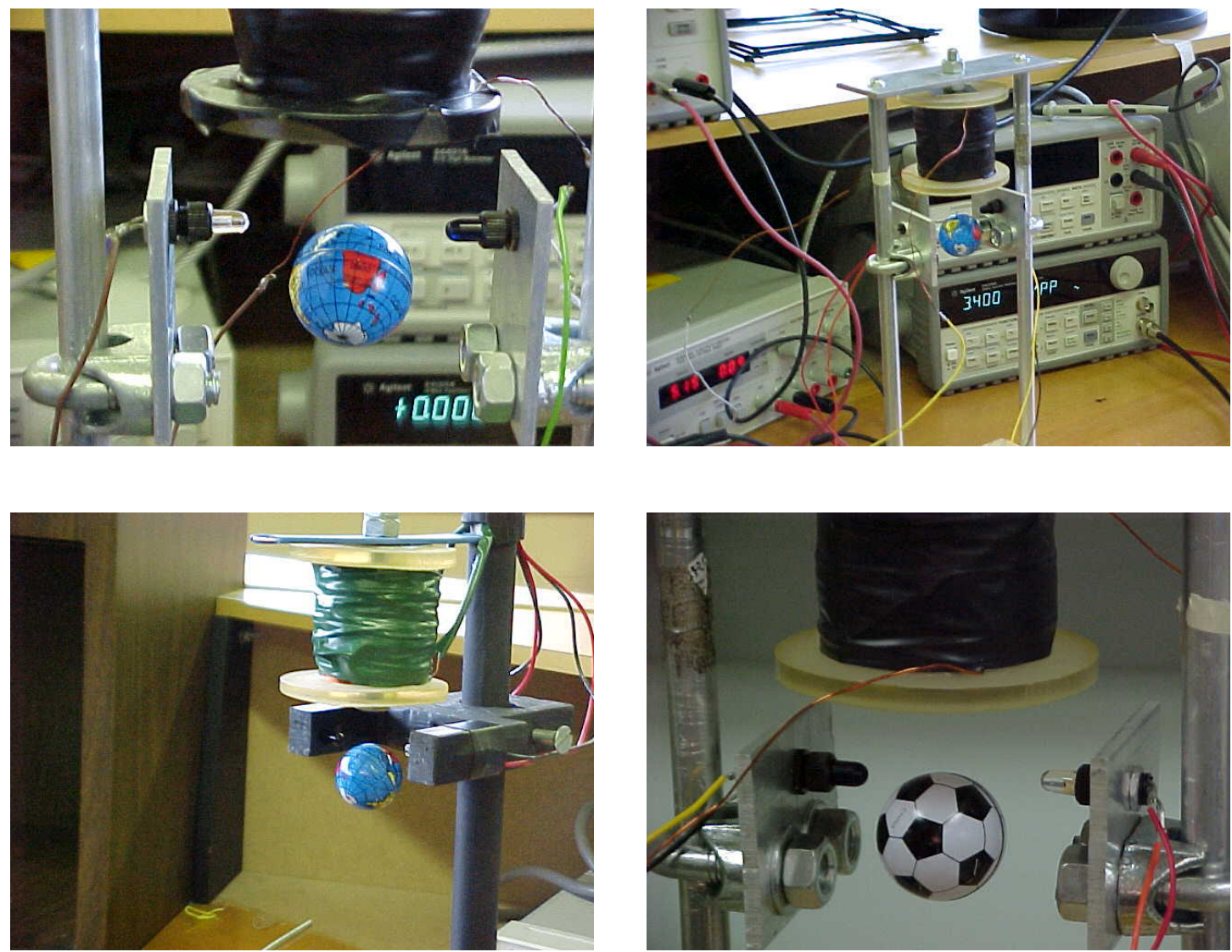


\section{Conclusions}

The students were surveyed several times during the progress of the course to determine their difficulties and aptitude for the subject matter. The beginning survey collected background information on the students, which served as a benchmark, and was used to assign teams. The mid-semester survey assessed conceptual difficulties, and provided feedback regarding the pace of the course. The final survey had 27 questions designed to evaluate various aspects of the course including course content, course speed, laboratory exercises, homework, quizzes, math usage, in-context learning approach, hands-on experience, and their overall satisfaction with the course. Ninety-five percent of the students indicated that the course enhanced their interests in engineering, and all students said that they would recommend the course to anyone interested in exploring engineering. Out of a class of thirty students, twenty-nine indicated that they would pursue engineering as a career field. The students also indicated that the course would be suitable for junior-senior high school students as a summer course, and would be an effective tool in recruiting high school students.

The success of this course verified that an experiential learning course could be taught effectively to freshmen students with basic algebra as a math prerequisite. The students' high level of enthusiasm in the course indicates that the course has the potential of attracting undeclared majors to the engineering field. With the word of mouth spreading to other students, the course is expected to gain popularity with time. The effect of the course on student retention will be studied in the next few years.

\section{$\underline{\text { Bibliographic Information }}$}

${ }^{1}$ L. R. Carley, P. Khosla, and R. Unetich, "Teaching "Introduction to Electrical and Computer Engineering” in Context," Proc. IEEE, vol. 88, pp. 8-22, Jan. 2000.

${ }^{2}$ http://www.geocities.com/area51/shire/3075/maglev.html.

${ }^{3}$ T. H. Wong, "Design of a Magnetic Levitation System-An Undergraduate Project," IEEE Trans. on Education, vol. E-29, pp.196-200, Nov. 1986

\section{Acknowledgements}

The author would like to acknowledge the University's Curriculum Development Grant in support of the development of the course.

\section{Biographic Information}

Hirak C. Patangia received his B. Tech. Degree (Honors) from Indian Institute of Technology, Kharagpur, India, M.Sc(Eng) degree from University of New Brunswick, Canada, and Ph.D. degree from McGill University, Canada. $\mathrm{He}$ is a Professor in the College of Information Science and Systems Engineering at the University of Arkansas at Little Rock. 